\title{
The Relationship Between Health Insurance and Out-of-Pocket Medical Expenditure in China
}

\author{
Zhaohan Liu* \\ Beijing Normal University-Hong Kong Baptist University United International College (UIC, Zhuhai, 519087) \\ *Corresponding author
}

\begin{abstract}
Health issue has aroused wide public concern in China. To some extent, insurance may decrease the cost of medical service. However, due to moral hazard (such as pianbao), people are more likely to use their health insurance. Both situations are possible in daily life. After running the regression using Stata and the data from China Health and Nutrition Survey, it comes to a conclusion that people may use more healthcare if they have health insurance. This paper provides a new idea about the relationship between insurance and expenditure. It ends by noting how Chinese government would deal with this kind of problem. Regulations and laws need to improve based on current legal system in the pharmaceutical industry.

Keywords: Health insurance, Out-of-pocket medical expenditure, Moral hazard, China Health and Nutrition
\end{abstract}

Survey (CHNS)

\section{INTRODUCTION}

This study will explore the effects of gaining health insurance on out-of-pocket medical expenditure in China. Nowadays, medical insurance issue in China's society has become the focus of people's daily life. Even though $95 \%$ of Chinese has basic healthcare insurance coverage, public health insurance only covers about half of the cost. Government tries its best to let citizens enjoy the benefit of full coverage insurance by releasing helpful policy. Therefore, the relationship between health insurance and medical expenditure would be a perfect topic. The article 'Does Health Insurance Decrease Health Expenditure Risk in Developing Countries?' actually gives a brilliant idea about this topic. From this article, the author uses estimation techniques to analyze descriptive statistics, in order to reach to a conclusion that having health insurance decreases the out-of-pocket expenditure. In other words, health insurance in China helps reducing patients' financial burden even though health insurance is still less generous than developed countries. Although this article was written long time ago, it still gave a sense of method towards this topic by using the latest information.

The idea of this topic comes from the contradictory relationship between gaining health insurance and paying out-of-pocket expenditure. On the one hand, out-of-pocket expenditure may decrease because insurance covers most of the medical cost so that citizens don't need to pay extra money for medical service. On the other hand, those people who have health insurance are more likely to use care, leading to moral hazard. Therefore, by engaging in immoral behavior, cost may increase by a large amount. In the past few decades, rates of health insurance coverage in China have risen, which also increases concern about this issue. The study will compare those with and without health insurance using the data from the China Health and Nutrition Survey.

After estimating using the empirical approach, it comes to a conclusion. The result for $\beta$ is 38.01 , which means that people who have health insurance may increase their out-of-pocket health expenditure by 38.01 RMB. These citizens realize the importance of insurance and would like to use more medical care to protect their own body than those who don't have insurance. First of all is personal fixed effect, for additional one year, the out-of-pocket expenditure drop by $1.08 \mathrm{RMB}$. For these elderly people, they may cover all the medical cost in their insurance, therefore, they don't need to pay for the extra out-of-pocket medical expenditure. Secondly, total out-of-pocket expenditure has some relationship with education. For average one education level higher, cost may decrease by 3.29 RMB. Most of the educated people know that it is illegal for moral hazard, so that they would behave well. Thirdly, province section shows that different places' out-of-pocket expenditure. For most of the places in various provinces, they indicate that this kind of medical cost may decrease by a large amount of money, ranging between 100 to $200 \mathrm{RMB}$. Only two places have the positive number under $100 \mathrm{RMB}$. The result shows that it is necessary to improve mechanism for medical insurance. Government should take action to eliminate insurance fraud to a low level nationwide. The final conclusion comes from the analysis of different variables, which is quite a persuasive result in the current situation.

\section{DATA}

The longitudinal data is from China Health and Nutrition Survey, which is an official website for obtaining dataset about Chinese health and insurance condition. There are 
many suitable datasets for this topic. Among all the factors, insurance, education and income are the perfect selections. The following paragraphs will describe the data in detail. The survey follows a large sample of communities, households, and individuals starting from 1989 to 2015 and is still ongoing. Also, there are over ten provinces included in the dataset, which makes the result more reasonable. First of all, it is the insurance section. In this survey, they ask people whether they have medical insurance or not. The percentage of two sides is quite close to each other. Besides, there are also $0.19 \%$ of the individual who don't actually know whether they have medical insurance. For those unknown and missing data, we should deal with them carefully as they may influence the final result. As for the description of personal health condition, most of the data is missing, which accounts for $66.78 \%$ of the total interviewees. The attitude for supplementary medical insurance is pretty negative. Only 1294 out of one hundred thousand people are willing to purchase this kind of insurance. Similarly, the result for employers to buy supplementary medical insurance for workers is even worse, less than $5 \%$ of the employees have those kinds of insurance to protect their interest. Most of the company would like to reduce cost so that they just skip this kind of spending.

Individual health care file shows a lot of information about personal health condition. For instance, have you been sick or injured in last 4 weeks? Most of the answers are no. Besides this question, there are many surveys about various kind of illness that may happen to people in their daily life. Another question is that whether it is inpatient or outpatient. Obviously, the number of inpatients is much less than outpatient. However, most of the data is missing due to some typical reasons and these data account for almost $90 \%$ of the total proportion. The average cost of treatment for the group is $4,862 \mathrm{RMB}$ per year for those 445 people who have the cost ranging between 0 and 99,999 RMB. Among the medical expenditure, the average percentage of cost to be reimbursed is $37.98 \%$. As for the money spent on illness or injury, the mean of the cost is RMB 708. In this cost, the cost paid by insurance makes up over 5 percent. It is not a big portion but is still useful to have insurance when emergency happens.

Education plays a significant role in this case. The higher education you receive, the more you may know about the importance of health insurance. From all the data in the study, there are various kinds of education level, ranging from no school up to 6 years college or more. The number of 3 years lower middle education level has the largest percentage.

Table 1 Descriptive statistics

\begin{tabular}{|c|c|c|c|}
\hline & Overall & No insurance & Insurance \\
\hline Age(year) & 37.01 & 36.44 & 38.59 \\
\hline Edu(year) & 17.96 & 16.56 & 18.64 \\
\hline Income (¥) & 1156.72 & 1462 & 1673 \\
\hline
\end{tabular}

The study includes many identified data. Survey year started from 1989 and last till 2011. The calculated age is 37 years old. The study did some survey in some provinces as well, including Beijing, Shanghai. Liaoning and so on. In these provinces, they have places like urban and rural area. After the calculation of 143564 places, the study shows that the places are more likely close to rural area. Finally, it is the wage variable. After interviewing about 47,000 people, the average number of hours worked last week was 34.21 hours out of 168 hours in total. Average monthly wage for more than 30 thousand last year is RMB1156.72 last year, most of them don't get a regular wage. Also, more than half of the interviewees don't receive cash bonus last year due to some reasons. Under this condition, the question 'other cash income last year' becomes meaningless, only one tenth of the total number of people has this kind of income. Besides cash income, some people have non-cash income. The percentage for this kind of people is much better than who has the cash income.

\section{EMPIRICAL APPROACH}

For this part, it needs to consider a lot of determinations. In order to estimate the association between health insurance and out-of-pocket health expenditure, the estimation follows specification

$O O P_{i c t}=\alpha+\beta H I_{i c t}+X_{i c t}+\theta_{i}+\phi_{c t}+\epsilon_{i c t}$ Where out-of-pocket expenditure $\left(\mathrm{OOP}_{\text {ict }}\right)$ represents person $\mathrm{i}$ in community $\mathrm{c}$ in year $\mathrm{t}$ is a function of their health insurance status $\left(H I_{i c t}\right)$, a vector of person-by-year controls $\left(X_{i c t}\right)$ including age, gender, career and education level, a person fixed effect $\left(\theta_{i}\right)$, a community-by-year effect $\left(\phi_{c t}\right)$, and a random error term $\left(\epsilon_{i c t}\right)$. The paper uses fixed effect approach to demonstrate the variables and the effect on out-of-pocket expenditure. 
Table 2 Regression result

\begin{tabular}{|c|c|c|c|c|c|c|}
\hline & $(1)$ & $(2)$ & $(3)$ & $(4)$ & $(5)$ & $(6)$ \\
\hline Have Insurance & 38.01 & -1.08 & -3.29 & 89.49 & -470.33 & 7.05 \\
\hline & $(18.45)$ & $(33.45)$ & $(1.47)$ & $(159.10)$ & $(823.92)$ & $(597.47)$ \\
\hline Person FE & $\mathrm{N}$ & $\mathrm{N}$ & $\mathrm{N}$ & $\mathrm{Y}$ & $\mathrm{Y}$ & $\mathrm{Y}$ \\
\hline Province FE & $\mathrm{N}$ & $\mathrm{Y}$ & $\mathrm{N}$ & $\mathrm{N}$ & $\mathrm{Y}$ & $\mathrm{N}$ \\
\hline Wave FE & $\mathrm{N}$ & $\mathrm{Y}$ & $\mathrm{N}$ & $\mathrm{N}$ & $\mathrm{Y}$ & $\mathrm{N}$ \\
\hline Province-by-wave FE & $\mathrm{N}$ & $\mathrm{N}$ & $\mathrm{Y}$ & $\mathrm{N}$ & $\mathrm{N}$ & $\mathrm{Y}$ \\
\hline
\end{tabular}

The coefficient of interest is $\beta$, and it represents the marginal effect of a change in insurance within an individual. The goal is to figure out what is the relationship between out-of-pocket expenditure and health insurance. If $\beta$ is positive, then it shows that if person who has health insurance may also increase their health spending by average $\beta$ amount of money every year. If $\beta$ is negative, then means the opposite way, they will decrease their cost on out-of-pocket expenditure. Besides health insurance status, the regression also includes a vector of person-by-year controls. Such as age, gender, career, and education level that are mentioned in the data section. Person-by-year controls may describe some main characteristics about different person so that the regression would tell you about whether there is any relation between health expenditure and person-by-year controls. The result may indicate whether some differences in person would affect their out-of-pocket expenditure. Same as community-by-year effect. By comparing data in various communities in different years, the regression may show the correlation between these two variables.

\section{RESULTS}

After the regression calculation, the result shows that people tend to increase their out-of-pocket medical expenditure when they have health insurance. This proves the assumption that people may use healthcare insurance more if they have health insurance. The $\beta$ is 38.01 , which means that people with health insurance may spend 38.01 RMB more than these who don't have health insurance. They are willing to make full use of the insurance so that they would like to spend more money building up their body. Sometime, this relates to moral hazard. The more out-of-pocket expenditure there is, the more government needs to pay for them. It might actually increase government's financial burden. Not only government but also insurance company may suffer from insurance fraud. Insurance companies will have hard time in dealing with extra unnecessary cost, which increase their difficulties in operation. 38.01 RMB seems to be a small amount of money, but most of insurance companies have many customers to serve. Therefore, the accumulated expenditure may cause many trouble for some small insurance companies.

Next is the person fixed effect. Age, education and income are the main variables that should be taken into consideration. Firstly, age is an important factor in health insurance. Elderly will pay more attention to health area. In the regression estimation, average one-year older, total out-of-pocket medical expenditure will decrease by 1.08 RMB. The possible reason for this is that elderly who over 65 may have a full health insurance coverage so that they don't need to worry about paying extra money to purchase any medical service.

Education is another significant factor. The higher education level, the more you will know about the function of health insurance and out-of-pocket expenditure. For every education level higher, out-of-pocket expenditure may drop by 3.29 RMB. After they realize the importance of health insurance, they may purchase insurance as soon as possible. Under this situation, they could reduce their spending on out-of-pocket expenditure due to the coverage of insurance.

Community-by-year effect gives a lot of information in the result. There are many communities by year variables in the dataset. However, most of the communities may decrease their out-of-pocket medical expenditure, only two of them are positive. In this two communities, they will increase their spending on health even though some communities already have full coverage of insurance.

\section{CONCLUSION}

To summarize, health insurance is becoming a popular topic for daily life. Public has raised the attention for the importance of having health insurance. However, it can be divided into two parts. On the one hand, having a health insurance may decrease out-of-pocket expenditure due to reason that it covers everything. On the other hand, these with health insurance prefer to use more insurance to check their body status. Therefore, it can cause more spending than others. After the calculation of regression, second opinion may be correct. Health insurance may lead 
to an extra spending in this situation. Sometimes, this kind of expenditure are kind of waste, they spend money on purpose to receive bonus. Government may suffer from financial crisis if everyone tries to act like this. Besides, insurance company may lose the money for helping people in need. Benefit-oriented hospitals and lack of strict laws are the two main reasons that cause this problem to happen. Hospitals are eager to gain profit from providing medical service so that they forget their industry standard. They can make money from moral hazard, of course they want to take this cation. After that, there are not many strict laws towards insurance fraud. Regulation organizations have no idea about what is illegal. Because of these factors, moral hazard still exists in health insurance.

In order to solve this problem, it should let government involve in the situation and take control of some unusual spending outsides health insurance. There should be some strict laws aiming at insurance fraud to protect the health insurance from being destroyed. Government and regulations should not skip this kind of immoral behavior. This act should be eliminated when it was young. Not only government, but also citizens should make their contribution. Once they see some illegal behavior, they can report to the relevant health supervision department. It is urgent to establish the reward system for reporting illegal behavior like insurance fraud. In this way, citizens are more willing to report in order to regularize medical service. The connection between government and citizens is important in dealing with moral hazard. With the participant of both party, there are bound to be a better environment in medical area.

\section{REFERENCES}

[1] Juergen Jung and Jialu Liu Streeter. (October 2015) Does Health Insurance Decrease Health Expenditure Risk in Developing Countries? The Case of China. Southern Economic Association

[2] Adam Wagstaff Magnus Lindelow. (October 2005) Can insurance increase financial risk? The curious case of health insurance in China. Health Economics 27

[3] Meng Q1, Xu L, Zhang Y, Qian J, Cai M, Xin Y, Gao J, Xu K, Boerma JT, Barber SL. (Mar 2012) Trends in access to health services and financial protection in China between 2003 and 2011: a cross-sectional study.

[4] Chen Chen (September 2016) Health Economic Analysis of China's Health Insurance System University of York

[5] Ling Li, Qiulin Chen and Dillon Powers (November 2012) Chinese Healthcare Reform: A Shift Towards Social Development. Sage Publications, Inc. 